\title{
A PROPÓSITO DE UN CANON ENIGMÁTICO DE RAMOS DE PAREJA
}

Javier GOLDARAZ

\section{A propósito de...}

Habitualmente hablamos de música "pura" o "abstracta" (sin referentes externos) y música "programática" (con tales referentes: poéticos, dramáticos, simplemente onomatopéyicos...). Tomemos un poema sinfónico puro, la obertura Fausto de Wagner (es un ejemplo más, hay montones). El motivo inicial de la tuba parece un mal tema para comenzar una sinfonia. Sólo cuando conocemos el correspondiente tema poético (Fausto hastiado del mundo) queda explícito su significado y recibe su justificación. La cuestión obvia es: ¿Añade algo o completa el placer estético la comprensión intelectual interna de un hecho artístico? ¿O por el contrario...?.

Aquí nos vamos a referir a otro tipo de adherencias con que a menudo ha contado la música, más externas si se quiere, o de diferente naturaleza que en el caso anterior. El punto de convergencia, y de discusión. sería precisamente la mencionada comprensión intelectual. Se trata de ejemplos de un simbolismo musical, una parte de las llamadas después figuras, muy cultivado en el Renacimiento y Barroco. No nos referimos a la asociación entre texto (elemento externol y música más afin a la expresión musical y que puede apreciarse auditivamente, la expresión de los sentimientos: el uso de la tonalidad mayor o menor para expresar alegria o tristeza respectivamente, del passus duriusculus, cuarta cromáticamente descendente, motivo de lamento en Bach, etc., ni a la fácil asociación entre música y programa (el canto del ruiseñor en la flauta del segundo movimiento de la sexta sinfonía de Beethoven), música y contenido textual (quintas descendentes sobre el sed descendam in infernum plorans en un motete de Josquin) o la técnica del leit motiv. Todo ello pretende, a veces, interpretar el texto o la idea 
poética de forma más profunda, extraerle todo su contenido. Lo hacemos a figuras (nótese el carácter espacial del término) de carácter más externo a la "pura" expresión musical. La lista no es exhaustiva ni se pretende una clasificación ${ }^{1}$. Su posible distinción y clasificación en simbolos, metáforas, pictogramas, poesia y retórica musicales, simple numerologia.... lo que se quiera, queda en manos del lector.

Uno de los primeros ejemplos de soggetto cavato procede de la misa Hércules dux Ferrariae, donde Josquin hace corresponder cada una de las vocales del titulo a las mismas vocales de las notas de un hexacordo (re-ut-re ut re-fa-mi-re). Es algo que perdura. B-ac-h (Sib-la-do"-si) "firmará" así su testamento incompleto, El arte de la fuga. El arte se realiza; el final de su vida y el de su obra se asocian dramáticamente, coinciden. Tal motivo cromático es además en él símbolo de pecado y sufrimiento. En el Concierto de cámara para piano, violín y trece instrumentos de vientos (c. 1924), Alban Berg expresa de la misma forma la divisa "Todas las cosas buenas van de tres en tres" en los nombres asi codificados de la augusta "trinidad" musical vienesa (Schönberg, Webern y él mismo); una obra, por otro lado, traspasada por el simbolismo del número tres. Josquin "mencionará" el texto tertia die mediante tresillos en el Credo de la misa De Beata Virgine. En las Visperas, Monteverdi simboliza la trinidad (texto: "et hi tres unum sunt") resolviendo en su momento una triada en el unisono. Schütz prácticamente dibujará una cruz (Si-do-Sol\#-La) sobre las palabras "und ge-kreu-zi" en su Historia de la Resurrección; en el motete de las Exequias musicales, la tensión ascendente de dich (a Ti) se resuelve en la unión, suenan juntos, de ich (el que exclama) y Dich (el Señor). En el madrigal italiano del XVI es usual expresar "morire" mediante un silencio repentino, usar notas blancas o negras para los conceptos correspondientes, una nota aguda para montaña o cielo, el efecto de eco para el espacio vacio. Se pueden asociar términos numéricos a las notas individuales, o estructurar numéricamente una pieza. En la Misa en Si menor de Bach, la

\footnotetext{
${ }^{1}$ No hay que ser especialmente sagaz para encontrar los ejemplos que vienen a continuación. Todos ellos están tomados de Ulrich Michels. Atlas de música. Madrid, Alianza. 1985. 1992.
} 
palabra "Credo" suena 7 veces 7, "in unum Deum", 7 veces 12 (el número de los apóstoles). "Et incarnatus est. 7 más 12, el "Crucifixus" tiene 12 acordes sobre 24 notas del bajo. Los ejemplos pueden multiplicarse hasta la saciedad. Estos acertijos musicales constituyen auténticos enigmas para el oido, superan sus capacidades. Sólo pueden descifrarse mediante la vista, el lema del texto, la razón analítica. Van dirigidos a colegas, a intérpretes expertos capaces de desentrañarlos. Algunos de ellos, los originales, fueron especialmente abundantes en la polifonia de los siglos XIV y XV. Entonces comenzó también a desarrollarse otro artilugio detectivesco, esta vez una forma musical: el canon enigmático.

Canon (de Kanon. regla, precepto), en términos musicales es, además de un instrumento de origen arábigo, la imitación estricta (canónica) de una voz (dux) por otra (comes). Se trata de una metonimia. El canon es la regla, la fórmula que rige tal imitación dando lugar a una estructura polifónica. La práctica precedió probablemente al término en las formas improvisadas tempranas de la música popular. Conocido el dux, los comites lo repiten de forma estricta. Se señalan el lugar de entrada, el número de voces, el intervalo (a la octava, a la quinta, a la cuarta, a la segunda; o más específico, ad epidiapentem, a la quinta superior, ad hypodiatessaron, a la cuarta inferior). De esta forma, sólo es necesario escribir el dux, los comites se "deducen" lógicamente de las reglas establecidas. Su ausencia efectiva más una regla deliberadamente oculta conducirản al canon enigmático ${ }^{2}$. La forma está emparentada con el motivo de la caza (caccia, chasse), la captura, en sentido estricto como metafórico: las voces se persiguen, huyen (la fuga viene de ahi), tanto en la caza real como en la amatoria ("venatorio" y "venéreo" pueden coincidir). El objeto de deseo puede se alcanzado (canon concluso; todas las voces se juntan en un

\footnotetext{
${ }^{2}$ En el Barroco. el canon pierde mucho de su primitivo enigma: se convierte en emblema, en divisa. En El Pliegue, Leibniz y el Barróco. Paidós. Barcelona, 1988, G. Deleuze dedica el último capitulo a "la nueva armonias. Podia haber sacado jugo a la forma canon, una melodia que se mira, se refleja a si misma, se repliega sobre si para estar acorde, después, consigo: no lo hace, a veces se acerca. Tiene chispazos. intuiciones esclarecedoras en medio del fárrago. Podrian extrapolarse para nuestro interés algunos de sus motivos: la annonia preestablecida leibniziana. la mónada. la "saturación" esquizofrénica, el sistema de rhingrave canons (pp. 155 y ss. de la edición española).
} 
calderón y finaliza) o quedar aplazado indefinidamente (canon circular, perpetuus, la rota latina, la rueda).

Puede haber otras asociaciones: al orden establecido, al poder. De ahi acabará derivando en el Barroco, a la dedicatoria, a la adulación del protector ("Ascendeque modulatione ascendat Gloria Regis" pone Bach en un canon en espiral de la Ofrenda musical dedicado al rey).

El canon puede complicarse. Un canon de grupos puede ser doble, triple, cuádruple. Cada comes puede tener diferente intervalo de entrada respecto al $d w x$, o quedar modificado (perdiendo lo estricto) al adaptarse a la respuesta tonal. El comes reproduce el dux en el mismo sentido o en sentido inverso. La inversión puede ser de dos tipos: de los intervalos (canon per motu contrario), reflejándose especularmente en un eje horizontal (cuando uno asciende. el otro desciende y viceversa, manteniendo los mismos intervalos); del sentido de la marcha, yendo en sentido contrario (la reflexión es ahora sobre un imaginario eje vertical. canon cancrizans o de retrogradación). Ambos procedimiento pueden combinarse. El comes puede reproducir el dux con diferente medida temporal, variando el tempo y el ritmo (canon de proporciones, per augmentationem o per diminutionem): aunque comiencen a la vez se irán separando paulatinamente. El canon circular puede derivar en espiral si el dux termina un tono por encima del inicio, de forma que en cada vuelta éste asciende ${ }^{3}$.

De todos estos tipos, el que ahora nos interesa (quizás el más sofisticadol es el canon enigmático. Se nos da el dux y hay que descubrir el intervalo y la distancia de entrada, la dirección de las voces, etc., es decir, el canon en sentido estricto, la regla, mediante un lema, habitualmente en latin y tomado del antiguo o nuevo Testamento o de invención propia. Asi pues, se nos presenta un enigma a resolver cuya clave, llave, es el lema a interpretar; enigma del canon que requiere una resolutio que nos lleva a la del canon. "Signa te, signa, temere me tangis et angis" es. por ejemplo, una conocida clave extra y autorreferencial; ella misma se deja leer igual

\footnotetext{
3 Iannis Xenaquis, "Dimensión matemática de la música". El Correo de la Unesco. Abril. 1986. pp. 4-9, relaciona todas estas posibilidades más o menos combinatorias y automáticas con los grupos de transformaciones matemáticos y, con los esquemas lógicos de la actual música serial.
} 
al derecho que al revés, un palíndromo; nos indica que se trata de un canon cancrizante. Tenida la clave, se resuelve el canon, es decir, se ponen las voces ausentes. Las soluciones y resoluciones pueden ser muchas (en los "Cánones polimorfos" de P.F. Valentini, hacia 1629, se ofrecen más de dos mil al "canone... sopra la parola del Salve Regina...").

Hay algo más. La partitura del dux y el lema (es nuestro caso) pueden estar inmersos en un motivo pictónico, en una ilustración, generalmente simbólica o alegórica. cuyos elementos figurativos pueden ser parte de la clave que nos dé la solución. Quizás no se nos indique donde está ésta. Otros elementos a tener en cuenta pueden ser una rúbrica, firma o dedicatoria que aparezca; visto desde el futuro pueden ser necesarios el conocimiento del contexto histórico de su producción (circunstancias externas, cartas, citas, referencias, conocimiento de la obra teórica, si la tiene, del autor, otros cánones enigmáticos suyos, de contemporáneos, etc.). El intérprete moderno debe afilar, pues, muchas armas en la interpretación de un canon enigmático: filología, juegos de palabras, iconografia, historia... y, por supuesto, música (no nos engañemos, se han resuelto casi todos. El gremio maneja un lenguaje y unas reglas comunes).

El canon como forma general ha traspasado todas las épocas. desde el primero conservado (un canon inglés, Summer, del s. XIII), hasta hoy (Bartok, Hindemith, Boulez) pasando por Bach, Mozart (en reuniones de salón; el canon no responde al ideal sinfónico ni operisticol Schumann o Brahams (sabido es su interés por Bach); tuvo especial brillo en la polifonia franco-flamenca de los ss. XV y XVI. Los tratados teóricos de la época lo consignan (Tinctoris, Adam de Fulda, S. Heyden, Glareano, Zarlinol recogiendo numerosos ejemplos de sus coetáneos. A mediados del XVI, en el auge cada vez mayor de la unión entre poesia y música, Vicentino califica ya el recurso de "non moderno" y la Camerata florentina, opuesta a toda polifonia, intentará relegarlo al limbo del recuerdo. Pervivirá en el stile antico, en la prima prattica de la que habla Monteverdi.

El canon ya voluntariamente enigmático, con su fusión de imagen, literatura y música, llega a su consecuencia lógica en los 
ss. XV, XVI y XVII ${ }^{4}$. Con el refinamiento en la notación musical que legó el ars nova del XIV la expresión gráfica pasa a primer plano, adquiriendo perfiles simbólicos. Un ejemplo conocido es el bello "Corazón Musical" de Baude Cordier del Códice de Chantilly (c. 1440), un rondeau a tres voces. Los pentagramas componen la figura de un corazón con sus notas en negro y rojo. En el texto, en negro, aparece a su vez la figura de un corazón en rojo ${ }^{5}$. Un canon a tres veces del mismo autor, Tout par compas suy composés tiene forma de circulo. En la misa de Josquin, di dadi supra naxagie aparecen sobre la voz del tenor dos dados como lema, indicando la clave, el valor de las notas en la voz canónica, la resolutio del canon. En 1597, T. Morley (A plaine and easie introduction...) nos presenta un canon en forma de cruz con sus versos explicativos, y un siglo después $\mathrm{J}$. Theile, un candelabro de ocho brazos, el "Harmonische Baum"6. El lector curioso puede consultar el libro final del Melopeo y Maestro (Nápoles, 1613) de Pietro Cerone, escrito en castellano. Aqui se nos presenta una sorprendente recopilación de diferentes cánones de diversos autores y propios dirigidos a refinar las habilidades de los estudiantes: el del sol, la balanza, el elefante, la cruz, las sierpes, los dados, el espejo, el caos, el "enigma del tablero de axedrez" de "Ghiselino Dancherts, todesco"... Algunos lemas: "Obtenebratus est in ortu suo". tomado de Isaías, 13, 10, en el primero, indicando que hay que oscurecer (hacer negra) la nota sol; "Tua nos exaltat humilitas" sobre el platillo superior de la balanza que contiene notas musicales y "Usque ad infimum descendam" en el inferior conteniendo la clave en el segundo. Al bajar la clave, suben las notas. Otro lema, "cum alpha, in diapason omega" nos señala que la nota final del tenor (omega) debe quedar una octava (diapason) más alta que la primera (alpha); "Qui prior canit \& canet ut ipse videt: Posterior vero pro nigris, albas; \& contra" en el tercero... No quiero ser prolijo, sólo ir abriendo boca para

\footnotetext{
${ }^{4}$ La obra capital sobre el simbolismo de la época es la de Willem Elders. Studien zur Symbolik in der Musik der alten Niederländer (Bilthoven: A. B. Creyghton. 1968).

${ }^{5}$ Puede accederse fácilmente a la ilustración en D. J. Grout. Historia de la müsica occidental, Madrid, Alianza. 1986, p. 155.

${ }^{6}$ Estos ejemplos están sacados de L. Robledo, «Los cánones enigmáticos de Juan del Vadow, Poesia. n ${ }^{0}$ 9. Madrid. 1980, pp. 91-104.
} 
enfrentarnos al canon de Ramos. Todavia siglo y medio después de Cerone, en España, el P. Soler incluye "algunos canones enigmáticos y sus resolución en la Llave de la modulación y antigüedades de la música (Madrid, 1762).

En el Renacimiento, el canon tiende al símbolo, en el Barroco a la alegoria. No es éste el lugar de fijar fronteras entre tales conceptos, de ver sus confluencias o su desarrollo histórico entre ambos periodos en lo que nos ocupa. El símbolo es más cerrado en si mismo, más autónomo, sin transposición al exterior, la interpretación no lo agota, a veces lo deforma, revierte a si mismo, no se realiza; la alegoria toca tierra, se deja traducir, tiende a la didáctico, a lo académico, a la divisa y el emblema? ${ }^{7}$ El emblema barroco nos hace comprender la alegoria mediante tres elementos: la imagen, la inscripción o sentencia y los nombres propios: ver, leer, dedicar (o firmar) ${ }^{8}$. Añádase la música (escrita) en el caso de ciertos cánones enigmáticos. Es la tendencia barroca a la fusión de todas las artes. La ópera lo intentará: música, palabras, acción. escenografia. La ilusión de tal sintesis, frustrada. llega hasta Wagner.

Más características barrocas: las imágenes tienden a salir de si mismas, a formar ciclos, series, historias, las inscripciones, en forma de predicado sin sujeto, a mantener una relación oscura con la imagen; remiten a un sujeto concreto poseedor de la alegoria ${ }^{9}$.

El canon del que nos estamos preocupando, renacentista. participa de muchas de estas caracteristicas, esquiva otras. La imagen está soberbiamente iluminada, destinada al disfrute de muy pocos (la corte florentina de Lorenzo el Magnífico), el lema hace referencia a la propia obra teórica de Ramos; otra inscripción es

\footnotetext{
${ }^{7}$ No se trata de valorar a uno y denigrar a la otra. W. Benjamin. en su tesis sobre el origen del drama barroco alemán. muestra que la alegoria no es un símbolo fallido sino algo diferente: «éste combina lo eterno y el instante, casi en el centro del mundo. pero la alegoria descubre la naturaleza y la historia según el orden del tiempo. convierte la naturaleza en historia y transforma la historia en naturaleza, en un mundo que ya no tiene centro». Las palabras son de G. Deleuze, op. cit., p. 151 de la ed. castellana.

8 Ibidem.

9 Ibidem. Véase el ciclo de los cánones enigmáticos de Juan del Vado. en L. Robledo. op. cit.
} 
una cita clásica, de Horacio. Y va firmado por el autor, firma que también puede tener connotaciones simbólicas. No está dedicado a nadie. Aunque inmerso en un cancionero en el que hay otras llustraciones, medallones, partituras, etc. es independiente de ellas, no forma historia o ciclo alguno.

En el Renacimiento la forma general canon está en sí misma aliada con lo oculto, con el enigma: ‘Canon est regula voluntatem compositoris sub obscuritate quadam ostendens" (el subrayado es nuestro) nos dice Tinctoris en su Diffinitorium (c. 1500) recogiendo la práctica musical de los cuarenta años anteriores. "Notate verba, Signate mysterian un siglo después Cerone, pero referido esta vez a un canon especificamente enigmático. Hay que preguntarse por qué en el Renacimiento, una forma musical regulada más estrictamente que ninguna otra, quizás por ello, admite la oscuridad, el enigma. El canon desemboca en canon enigmático. Se ha pretendido con cierta frecuencia relacionar directamente el estilo musical con las condiciones económicas y sociales de determinada época. Así, el paso del mundo feudal teocéntrico (jerarquizado), al de artesanos y comerciantes (gremialismo, individualismo, racionalismo técnico) con el paso de la monodia (con el ideal de obediencia que expresa) a la polifonia (estructura "gremial", voces individuales, polarización vocal calculada). Una misma visión del mundo estaria bajo las diferentes artes: polifonia y perspectiva (un todo ordenado, ), las nuevas terceras mayor y menor constituirian los "puntos de fuga" dotando de profundidad al "espacio musical", etc. ${ }^{10}$ No sirve de mucho. Claro que para proponer ilustrar y resolver enigmas hace falta un tiempo ocioso sólo posible en determinada estructura social, etc., pero el argumento es excesivamente general y a veces rebuscado cuando queremos establecer relaciones directas. otra posible conexión seria con el hermetismo, cábala y ocultismo renacentistas que ha tenido ya ilustres investigadores (Yates, Debus). Otras artes tambiẻn lo reflejan: Gargantúa y Pantagruel no sólo oculta bajo un cuento inocente de gigantes oscuros significados doctrinales sino que el último capitulo del primero es un largo poema titulado precisamente Enigme en Prophétie, describiendo un

\footnotetext{
${ }^{10}$ Véase, entre otros. Henri Pousser, Música, scmántica, sociedad, Alianza. Madrid. 1984.
} 
juego en un lenguaje profético y apocaliptico. No hay que ir tan lejos: la ortodoxia contiene los escritos de S. Pablo o las propias parábolas de Cristo en las que la verdad necesita para su expresión el ropaje simbólico, la interpretación, el sentido oculto. Después están Platón, los mitos clásicos, la teologia negativa del Pseudo Dionisio, León Hebreo, la tradición medieval del significado de las Escrituras (literal, moral, alegórico)... No todos los enigmas y metáforas obedecen a la misma necesidad o arbitrio. Están la inefable experiencia mística, el afán poético, la jerga especializada, el mensaje cifrado, la mente retorcida, el puro juego ${ }^{11}$. Como el mago renacentista, el promotor de enigmas musicales no sólo es capaz de descifrar la realidad sino que la manipula, está detrás de ella, la crea, toma el lugar de Dios. Hay un sujeto tras la realidad enigmática. Ello nos obliga a una doble interpretación, la propia del histoniador del arte o de la música que decodifica los usos, los comportamientos, el contexto, el mundo simbólico del pasado y la del receptor directo del enigma (también va dirigido a él). El compositor de enigmas nos convierte en su contemporáneo.

Una forma más fácil de explicación del auge de los rompecabezas, jeroglificos y puzzles de toda laya aparecen en los siglos XV y XVI en el panorama musical es acudir a la propia técnica compositiva de los compositores músicos: el propio sistema regulativo de la forma canon, el desarrollo de las formas gráficas de representación musical procedente del ars nova, ya se ha dicho, que convierte la música en imagen. El tiempo, la esencia de la música, se congela, se hace espacial, se divide en partes: texto, caligrafia, figura, simbolo, mensaje polimorfo, concepto. El significante se convierte en significado, el simbolo en objeto de representación reflejando las maneras propias de una sociedad cortesana extremadamente refinada. Desde finales del XIV y hasta la segunda mitad de XVI todos los compositores cultos importantes son de la misma extracción, borgoñones, franco-flamencos, hasta que toman el relevo los italianos. Crean una especie de casta aristocrática, se reparten por las cortes europeas, se conocen y entienden entre ellos, manejan un idioma común. Una técnica habitual de composi-

${ }^{11}$ Se han intentado diversas tipologias. Vease, por ejemplo, D. P. Walker, «Esoteric Symbolism*, Variorum Reprints, Londres. 1985. en lo referente a lo religioso. 
ción es la cita musical, el guiño, la parodia. Se toma un motivo musical anterior, un tema preexistente y se vuelve a reproducir en otro contexto, en otra voz, con otro texto, enmascarado en otro código. Un cantus firmus gregoriano puede convertirse en una contradanza. Sólo el experto, el erudito amigo es capaz de apreciarlo, la mayoria, el oyente común queda in albis. Un elemento pertenece asi a contextos diferentes entre los que puede establecerse una relación de indole fundamentalmente racional ${ }^{12}$. Los compositores se envian mensajes cifrados en el texto-música que sólo los colegas pueden descifrar. Autorreferencia de clase y oficio. Retomemos, ahora de forma extrema, el problema inicial: lo racional puede destruir la unidad de la expresión artística. Los cánones enigmáticos valen poco o nada auditivamente, como música. En nuestro caso, lo veremos enseguida, el complejo simbolismo habrá vampirizado la expresión musical. De nuevo Cerone: "Voce parum aures, plus oblecto enigmate mentem" (me atrevo a traducir: "Poco agrado a los oidos con el sonido. más a la mente con un enigman.). La razón analítica se convierte en el órgano del enigma que, desmembrado, hay que reconstruir. Diversifica la "unidad artistica" temporal. Toda obra de arte redonda sólo tiene una solución, el enigma muchas resolutiones (mysteria está en plural), balbucea entre lo real y la interpretación que explota en una pluralidad de significados. Quizás todo comienza con juegos, con bromas. En el s. XV, P. Fontaine firma Fontaine a vous dire le voir. Un tal Jacques Vide en Las j'ay perdu mon espincel retrata a una dama que se queja de haber perdido la pluma que le regaló su amado: la parte del contratenor no está escrita, queda el hueco en la página, como reflejo mudo que hay que rellenar ${ }^{13}$. El músico es poeta y pintor (describe y-muestra) de un espacio en blanco, de un hueco que hay que reconstruir (¡qué edificio conceptual no hubiese construido Derrida sobre la canción borgoñona!). Trento se dio cuenta de los artilugios de la razón, de la nula efectividad sobre la masa de la

\footnotetext{
${ }^{12}$ El procedimiento, privado de su artificio conceptista ha perdurado. En Fuegos de artificio de Debussy, resuenan fragmentos de La Marsellesa: Saint-Saëns usará un motivo de la "danza de los "silfos" de Berlioz para, en otro ritmo, aplicárselo al elefante, etc.

${ }^{13}$ Véase Marix, ed. Les musiciens de la Cour de Bourgogne au XVe sclecle (14201467). Paris, 1937.
} 
música sofisticada, hermética. Le antecedió a ello el protestantismo. Habia que restituir una música comprensible, auditivamente comprensible, que emocione, que transporte, que haga llorar, rezar... a todo el mundo y a favor de la misma fe. Una cruzada contra lo racional, lo abstracto. lo elitista, la diseminación de significados, la clave secreta que restituye la sospechosa unidad perdida; propondrá, tampoco podia apuntarse a lo moderno del recitativo, una polifonia homofónica, sin pluralidad de textos, de lecturas, el pueblo unido bajo una única pauta directriz. A finales del XVI, Hernando de Cabezón dirá ya: “... el deleyte del oir, cuyo objeto es la Músican.

Un canon enigmático de Ramos de Pareja.

Bartolomé Ramos de Pareja nace en Baeza (Jaén) hacia 1440. De pequeña estatura y carácter turbulento, ocupa la cátedra de música de Salamanca donde redacta su obra principal y hace algunas composiciones hoy perdidas, manteniendo animadas disputas con Tristán de Silva y Pedro de Osma. Pasa a Italia, polemiza con Tinctoris y J. Hotby estableciéndose en Bolonia, donde publica su Musica practica en 1482. Considerado una polémica autoridad musical recibe las duras criticas del erudito milanés Gaffurio y del envidioso N. Burzio, aunque tiene fieles discípulos como G. Spataro. El objeto de la polémica es siempre la actitud "empírica" de Ramos, su apego a los dictados de la práctica musical frente a la auctoritas tradicional, lo que le lleva a echar por tierra el sistema modal guidoniano y proponer una nueva afinación para la escala diatónica. Se le ve en Roma poco antes de su muerte, en 1498. Se ignora si estuvo en Florencia, donde aparece el canon que vamos a examinar.

En el capítulo cuarto del tercer libro de su obra teórica trae Ramos ejemplos de algunos cánones (en realidad son fugas) de otros autores y propios: en el motete Tu lumen, pone: "In perfectione minimorum per tria genera canitur melorum", dando a entender el valor de las notas y los intervalos de las respectivas voces según los géneros clásicos (una tercera menor, un tono y un semitono); en otro, la clave "Requiescat in pace" indica que no se pone la nota re: igual, "Ut Requiescant a laboribus suis", pero "Si tenes cum Domino AGAMENON, de capite nullos...", indica que han de 
ponerse de nuevo las notas eliminadas en el anterior, etc. Antes habia definido canon como: "Canon vero, quia est quedam regula voluntatem componentis sub quadam ambiguetate obscure et in enigmate insinuans".

Pero el canon que aquí nos ocupa es el que aparece en el frontispicio de un precioso cancionero prodigiosamente ilustrado de la época de Lorenzo el Magnífico, que se conserva en la Biblioteca Nacional Central de Florencia con la signatura "MS Banco Rari 229". Contiene composiciones de Isaac, Agricola, Busnois, Josquin, Obrecht, etc. Los iluminadores son en su mayor parte. los hermanos Gherardo y Monte di Giovanni ${ }^{14}$.

Nuestro canon aparece en el folio $\mathrm{III}^{`}$, como frontispicio del cancionero. Cuatro vientos IOriens, Occidents, Septentrion y Meridion) en gris sobre fondo azul soplan en las cuatro direcciones hacia un pentagrama circular con sus notas. Los nombres, el pentagrama, las notas y todas las inscripciones están grabadas en oro. El canon circular es una clara imagen del universo en la que las líneas del pentagrama semejan órbitas planetarias; para acentuar la circularidad, el pentagrama carece de clave, parte del enigma a descifrar. En los bordes internos de éste se lee: "Mundus * et musica * et totus concentus * Bartholomeus Rami" ("El mundo y la música y la armonia total".) La clave del canon, en el centro del círculo, reza: "Sive lidium in sinemenon sive ypolidiu(m) diaçeugmenon p(er) quatuor quarta(s) duca(s) renova(n)do dulcem harmoniam intra diapason se(n)ties melodia(m) bene modula(n)do"15 ("Si llevas mediante cuatro cuartas, bien el lidio a synnemenon, bien el hipolidio a diazeugmenon renovando la dulce armonia en la octava, oirás una melodia bien modulada"). Es una clave puramente musical que refiere a la propia obra teórica de Ramos. En la parte inferior de la lámina, dos angelotes de alas verdes sostienen una especie de paño rojo con la leyenda: "Omnibus hoc vitium est cantoribus, inter amicos ut nunquam inducant animum cantare

\footnotetext{
${ }^{14}$ Hay edición moderna: A Florentine Chansonnier from the Time of Lorenzo the Magnificent. Ed. por Howard Mayer Brown. Un. of Chicago press, Chicago and London, 1983.

${ }^{15} \mathrm{El}$ final es una cita de Casiodoro, Institutiones: "Musica est ars bene modulandi". de raigambre agustiniana.
} 
rogati, iniussi numquam desistant". ("Todos los cantores tienen este vicio; requeridos a cantar entre los amigos, nunca se deciden; no requeridos nunca paran ${ }^{\text {16. }}$.)

El canon asocia claramente la música en sentido estricto con la música cósmica, trayéndonos Ramos en su propia obra la repetida clasificación boeciana en música mundana, humana e instrumentalis (lo veremos enseguida). El viejo concepto de que una misma armonia (concentus) rige el cosmos, el hombre y la música fue revitalizado en el renacimiento neoplatónico florentino bajo la férula de Ficino ${ }^{17}$. Pero tal relación puede ir más allá del tópico en el caso de Ramos al concretarse en sus dos innovaciones fundamentales: el establecimiento de la octava como unidad estructural de la música y un nuevo sistema de afinación.

Es sabido que en Grecia, la octava esta compuesta de dos tetracordos disjuntos(Meson, Mi-la y Diezeugmenon, si-mi). Para evitar el disonante tritono ("diabolus in musica") que se crea entre Fa y $\mathrm{Si}$, se introduce un nuevo tetracordo superpuesto a los anteriores (Synemmenon, la-re, con el Sib). Así aparece en una ilustración en el primer libro de la Musica practica de nuestro autor. Los tetracordos Diezeugmenon y Synemmenon tienen la misma sucesión de tonos y semitonos y están separados por una cuarta.

Uno de los problemas mas desconcertantes con los que se enfrentaron los teóricos renacentistas fue la conexión que parecia haber en la teoria musical griega entre tonos (alturas de las escalas) y modos (diferentes organizaciones tetracordales internas). Ambos

${ }^{16}$ Se trata de una broma erudita refrendada por una autoridad clásica. Proviene de la Sátira III 1-3 de Horacio. Tal cita debia ser bastante común. Clemente Terni en su edición y comentario a la Musica Practica de Ramos. Joyas Bibliográficas, Madrid, 1983. encuentra estos versos traducidos al italiano en la Florencia de la primera mitad del s. XVI: "Fra gli amici. I Cantori han questo vizio/ che mal non voglion cantar se son pregati/e non richiesti ogn'or van biscantando" (L. Pargi. Laurentiana. L. S. Olschi. Florencia, 1954, p. 72). En Terni. p. 296.

17 Véase, entre muchos otros, P. O Kristeller. The Philosophy of Marsilio Ficino, N. York, 1943; D. P. Walker. "Le chant orphique de Marsile Ficin" y "Ficino's spiritus and music", Variorum Reprints, Londres. 1985: L. Spitzer. Classical and Christian Ideas of World Harmony. Baltimore. 1963. En un excelente grabado que aparece en su Practica musical (Milán, 1446). F. Gaffurio relaciona los nombres griegos de las notas. planetas, modos y musas. Véase su reproducción en $\mathrm{E}$. Wind, Los mistertos paganos del Renacimiento. Barral. Barcelona, 1971. lámina $n^{2} 20$. Lo toma precisamente de su vilipendiado Ramos. Música practica. III. 3. 
tenian nombres comunes: Dorio, frigio. lidio. Diversos autores parecian traer soluciones diferentes a una practica clásica ya desaparecida. Ramos no resuelve el enigma, pero lo tiene presente; volcado más en la música practica del momento, era un illiteratus, como lo calificó Galfurio, aunque conocia bien a Boecio. Hubo que esperar a Salinas y Mei para dar con la clave mediante la lectura de Ptolomeo. Sin embargo, aqui Ramos parece señalarnos tal conexión.

Los modos son diferentes configuraciones interválicas (disposición de tonos y semitonos) que puede adoptar una octava. El modo lidio puede llustrarse como la sucesión interválica que se da en la octava Do-do con el Sib. El hipolidio (una cuarta, diatessaron, más grave) la de Do-do con el Si natural. Mezclando ambos conceptos, el fragmento de la clave "Sive lidium in sinemenon sive ypolidium diaçeugmenon" puede interpretarse: comenzar en la nota Fa (modo lidio), usando el Sib (tetracordo synemmenon) o en Do (hipolidio), con el Si natural (tetracordo diezeugmenon).

Modos y tonos, relacionados en la clave, lo están en la obra teórica de Ramos con y mediante la octava. Ramos es el primer teórico en introducir la octava en la forma actual, Do-do, dejando atrás la estructura tetracordal griega y la hexacordal medieval. Lo hace fijándose en los prácticos (aunque propone denominar las notas: Psal- li- tur per voces- is- tas-. Cantada, la frase es autorreferencial). El modo lidio puede transportarse al hipolidio manteniendo el mismo orden de intervalos. Para ello basta tomar otro inicio de la octava. Estamos en los albores de la tonalidad: si la escala Dodo, con si natural, la transportamos a Fa-fa, con el Sib, el orden interválico permanece inalterable, cosa que no ocurre permaneciendo en Do-do usando la nota Sib. En el último caso cambiamos de modo (de Jonio o hipolidio a Lidio); en el primero mantenemos el mismo. Ello es posible porque la octava puede comenzar en cualquier nota, es circular: "octava (nota) vero similis est primae..." ${ }^{18}$. Las caracteristicas modales han desaparecido en pro de

18 Musica Practica I, 3. Las referencias a este hecho son constantes:"inter prima et octavau maxima conformitatis affinitas similitudoque reperitur, adeo ut differe non sentiatur nisi penes acuminis gravitatisque diversitatem (...) non viginti (como anteriormente) sed septem tantum sunt (liversae litterae). post quas non aliae, sed eadem quasi iterum renascuntur...". Ibiden. "Dictum est totum corpus musicae unaun esse diapason quae octo vocibus constat..." Ibidem II. 1. 
la tonalidad (puede comprobarse transcribiendo y haciendo sonar la partitura del canon). La octava es circular, como el movimiento de los cielos, dirá después Salinas (1577) comentando a Ptolomeo en cita que no he podido encontrar. La idea esta presente en la propia música del canon: su ámbito ocupa exactamente una octava. Por otro lado. Ramos utiliza a menudo en su obra teórica el poco convencional termino "totus concentus" para referirse a la octava, término que aparece en nuestra figura aplicado a "mundus et musica".

En uno de sus excelentes articulos, E. Lowinsky relaciona la revolución copernicana con el tratamiento renacent ista de la octava: esta ocupa el mismo lugar entre los intervalos musicales que el circulo entre las figuras geométricas ${ }^{19}$. La tesis de Lowinsky de que gran parte de las concepciones musicales renacentistas están representadas en términos espaciales no debe ser, no obstante. exagerada. Traer aquí a Copérnico puede estar de más; se ignora además que las connotaciones espaciales de la música (en cosmologia, arquitectura, ilustraciones, etc.) viene de antiguo ${ }^{20}$. El Barroco romperá el circulo, descubrirá el pliegue, la elipse. En el Renacimiento, Ramos será el primero en destacar la circularidad de la octava, luego vendrán Heyden, Aron, Vicentino, Fogliano, Tovar, Zarlino, Salinas... convirtiéndose en un tópico, hasta hoy dia.

Pero la modalidad tiene en Ramos carácter simbólico, siguiendo la corriente de la época. Ambos modos, opuestos en su carácter, están a su vez emparentados con la música humana (un carácter) y mundana (un planeta y un dios o diosa). He aquí lo que dice

\footnotetext{
$19 . "$... circle and sphere played a very important part in the Renaissance concept on spatial organization. There are phenoment in the musical development during the Renaissance that are comparable to the interest in the circle. One is the new enthusiasm for the interval of the octave (...). The octave take the same place among musical intervals as does the circle among geometrical figures". E. Lowinsky. "The concept of Physical and Musical Space in the Renaissance". Papers of the American Musicological Society. $1941 . \mathrm{pp} .75$ y 77.

20 Vid. J. Haar. Musica Mundana, Variations on a Pythagorean Theme. Harvard Un. Chmbridge. Mass.. 1960. pp. 399 y ss. Aqui relaciona el autor un diagrama de circulos en espiral con el cmblema renacentista de la serpiente que se muerde la cola. el movimiento de los cielos. el movimiento circular del sonido. el espacio vitrubiano organizado en ténninos musicales, visible y audible, ete. Podria intentarse explorar algunos de estos caminos.
} 
Ramos sobre los modos lidio e hipolidio en Musica Practica (III, 3); "Hypolidius vero ipsi Veneri est atributus, que fortuna est, feminea tamen, quia provocat ad lacrimas pias quandoque. Lidius vero lovi, fortune maiori, qui homines sanguineos et benevolos creat mitesque atque iocundos, recte comparatur, cum semper gaudium notet. Convenientia cum Venere in diathessaron atque in bonitatis fortuna concordant nec differunt nisi vocum differentia. Inferior enim vox non ita dulcis est sicut acuta neque suavis". ("El hipolidio se atribuye a Venus, que es la Fortuna; femenina al fin. porque (este modo) provoca a veces lágrimas de piedad. El lidio se compara adecuadamente a Júpiter, la mayor fortuna, que crea hombres sanguineos y benevolos, amables y alegres, porque siempre indica alegria. Concuerdan por convención con Venus en el diatessaron y en la fortuna de la bondad y no difieren sino en la diferencia de los sonidos. La voz inferior, en efecto, no es tan dulce y suave como el agudo"). La conexión de "fortuna feminea" con Venus y "fortuna maior" con Júpiter se remonta a la mitologia clásica. Ambos modos están relacionados; el modo lidio no es sino el hipolidio una cuarta mas arriba. En Ramos es este modo el que marcaria la pauta, como lo es Venus en un simbolismo que podria todavia prolongarse ("... que vero lectitiam indicat Veneri", por ejemplo).

Hemos establecido ya algunas conexiones: el canon circular, el cosmos, la octava, la Fortuna (y su rueda) bajo la advocación de Venus. Vayamos a la música escrita. ¿Donde comienza? Es claro: los cuatro vientos nos lo dicen con su doble significado de soplar hacia el cosmos y emitir la voz del canto. El viento que sopla del este (oriens) esta privilegiado: sopla por una concha, aliada de Venus. La primera voz (tenor o alto) comenzara en esa nota; cuando la melodia llegue a la nota sobre la que sopla el del sur (meridion) comenzara desde el principio la segunda voz, etc. Los vientos hacen de signa congruentia, marcan las entradas de las voces. No hace falta transcribir la música, no nos importa ahora tanto el valor musical como el pictórico. Podemos comenzar en la nota $\mathrm{Fa}$, con todos los Si bemoles o en Do, con los Si naturales de acuerdo a la clave descifrada por ahora. Tenemos ya una primer resolutio del canon, o mejor, dos según la nota inicial. Pero hay más: podemos interpretar, avanzando en el lema, "Sive lidium in sinemenon... per quatuor quartas ducas renovando dulcem harmoniam..." como: iniciar el tema en el modo lidio y subirlo a synemmenon, una cuarta 
mas arriba, en el segundo fragmento, otra en el siguiente, etc. de esta forma, concuerdan las "quatuor quartas" de la clave con los cuatro segmentos de la partitura (el modo lidio está ya una cuarta por encima del hipolidiol y con el termino "renovando dulcem harmoniam". En su obra teórica Ramos usa indistintamente "quarta" o "diatessaron" para referirse al intervalo de cuarta. Podria interpretarse entonces, tanto que la primera voz sube una cuarta sobre la partitura escrita al llegar a la entrada de la segunda, como que continua tal como está escrita y que las siguientes voces van entrando una cuarta por encima sobre lo escrito. Es decir, en un caso, la melodia cambiaria de tonalidad ( $\mathrm{Fa}$. Sib, Mib, etc.), en otro, cada una de las voces estaria en tonalidades diferentes a distancia de una cuarta ( $\mathrm{Fa}, \mathrm{Sib}, \mathrm{Mib}$, etc.). Ahora se excederia el ámbito de la octava entre la voz mas grave y la mas aguda. Habria que reinterpretar entonces la continuación de la clave, "renovando dulcem harmoniam intra diapason senties melodiam bene modulando" como "renovando la dulce armonía que se encuentra dentro de la octava". Otra posibilidad mas improbable seria bajar una octava, para no exceder sus limites, cada vez que se sobrepasan estos. En cualquier caso, surgen dos innovaciones sobre la practica musical: la enorme ampliación del espacio sonoro y el exagerado cromatismo a que daria lugar (cada cuarta añadirla un bemol mas a la melodía original). El propio Ramos nos dice que el gamut guidoniano existente en su época podia ser superado; Lowinsky incide en la ampliación del espacio sonoro en el Renacimiento ${ }^{21}$. En cualquier caso, hay que tener en cuenta que los canones enigmáticos pretendian más ser ejercicios de imaginación que una partitura musical que, descifrada. pudiese llevarse a la práctica. Si el canon fuese circular, si se prolongase indefinidamente, el espacio sonoro aumentaria indefinidamente, así como el cromatismo en los dos primeros casos.

El aumento del cromatismo nos introduce en un problema importante relacionado con la segunda de las innovaciones propuestas por Ramos en su obra teórica que hemos señalado: un nuevo sistema de afinación. En la afinación imperante hasta entonces, la pitagórica, doce quintas exceden a siete octavas en la

\footnotetext{
21 E. Lowinsky, op. cit.
} 
llamada comma pitagórica (24 Cents). Eso hace que sonidos enarmónicos (Do\#-Reb, Fa\#-Solb, etc.) no coincidan pudiendo prolongarse indefinidamente el circulo de quintas o dicho de otra forma, la octava tendria un numero infinito de notas. En la practica llevaba a la imposibilidad de usar todas las alteraciones habituales hoy dia. Ramos es el primero en establecer en una obra teórica su nuevo sistema de afinación para la escala diatónica consistente en usar terceras mayores y menores justas $(5 / 4$ y $6 / 5$ respectivamente). Para ello reduce la quinta, Sol-Re en una comma sintónica (22 Cents), haciéndola impracticable, pero ahora el circulo de quintas puede cerrase, que es lo que se pretende, entre Do\# y Lab pues la distancia ha quedado reducida a un schisma (diferencia entre ambas commas, 2 Cents) ${ }^{22}$. El aumento de alteraciones no seria óbice para la interpretación puesto que ahora equivalen Lab a Sol\#. Reb a Do\#, etc. Ramos inicia ahi el camino hacia la justa entonación que culminan Zarlino y Salinas.

Puede pensarse que estas interpretaciones están traídas por los pelos o son excesivamente sofisticadas. No es así. La existencia de diversas armaduras en las claves de una composición polifónica o el cambio de armadura en la misma voz (siempre bemoles; la parte grave, un bemol más que la aguda inmediata), producto del uso simultaneo de diversos modos o del cambio de modo en el transcurso de la composición es una practica habitual en el s. XV y parte del XVI. Muchas veces, las alteraciones no aparecen escritas, regulándose por las leyes de la musica ficta. En una serie de artículos, E. Lowinsky analiza determinadas composiciones musicales renacentistas, todas ellas bajo el signo de la circularidad y la advocación de la diosa Fortuna, un motivo simbólico ampliamente usado en el Renacimiento y en especial en la corte florentina de los Medici.

La primera es una pieza del príncipe de los compositores renacentistas, Josquin Desprez titulada Fortuna dun gran tempo, que utiliza un material temático muy usado por otros compositores y aparece en el Odhecaton impreso en Venecia a principios del s.

\footnotetext{
${ }^{22}$ Sobre estos asuntos, vid. J. Goldáraz, Afinación y temperamento en la musica occidental. Alianza. Madrid. 1992.
} 
XVI por Petrucci ${ }^{23}$. La composición es a tres voces, pero presenta la particularidad de que cada voz tiene diferente armadura: el discanto esta en Do mayor (sin alteraciones), el tenor en Fa (con Sib) y el contratenor en Sib (con Sib y Mib), terminando en la nota Fa que pertenece a las tres tonalidades. La obra esta concebida para ser interpretada y muestra la maestria compositiva de Josquin, pero a lo largo del desarrollo se dan múltiples disonancias inaceptables, producto de las diferentes armaduras: $\mathrm{Si}$ natural contra Sib, Mi natural contra Mib, Sib contra Mi natural (tritono), etc. Lowinsky acude a las leyes de la musica ficta imperantes en la época para solucionar el enigma. Según este autor, durante los siglos XIV y XV aparecen escritas las alteraciones en la partitura, desapareciendo hacia 1450 sin que se sepa muy bien por que. En otro texto hablara de un "secret chromatic art" en la musica reservata holandesa del s. XVI ${ }^{24}$. La etimología del termino de esta ultima no es muy clara. En 1565, Samuel Quickelberg la define como "ad res et verba accommodando, singulorum affectuum vim exprimendo, rem quasi actam ante oculos ponendo". El intérprete debia poner las alteraciones no escritas para exprimir el significado textual y mostrar sus imágenes, tal era el secreto (parece que el Renacimiento esta lleno de secretos musicales). No hace falta decir que el autor recodifica la pieza de Josquin con sus correspondientes alteraciones. Al lado de los ejemplos que aparecen en los artículos

\footnotetext{
23 E. Lowinsky. "The Goddes Fortuna in Music". Musical Quarterly. 29 (1943).

24 E. E. Lowinsky. Secret Chromatic Art in the Nedherlands Motet Columbia Un. Press, N. York. 1946. La posición de Lowinsky ha sido criticada por Leo Schrade: "A Secret Chromatic Art". Musica Disciplina I.1946. El problema de las diferentes armaduras en una misma composición durante los ss. XIII y XVI ha dado lugar a enormes disputas entre los especialistas actuales. Sobre el espinoso tema del uso simultaneo de diferentes alteraciones en la clave, su significado y relación con el sistema hexacordal de solnisación y las leyes de la musica ficta véanse: E. Lowinsky. "The Function of Conflicting Signatures in Early Polyphonic Music", Musical Quarterly, XXXI (1945), quien critica opiniones anteriores, en especial los de Willi Apel, "The Partial Signatures in the Sources up to 1450". Acta Musicologica X (1938). pp. 1-13 y XI (1939). pp. 40-42. La polémica continuó con R. H. Hoppin. "Partial Signatures alla Musica Ficta in Some Early 15th-Century Sources". Journal of the American Musicological Society. VI (1953). pp. 197-215. E. Lowinsky. "Comflicting Views on Conflicting Signatures". IX (1956). pp. 97-117. En estos excelentes articulos pueden verse todo tipo de ejemplos sobre cambios modales. aumento de alteraciones, etc., desde la Edad Media hasta bien entrado el Renacimiento en lo que debia constituir una practica habitual de la época.
} 
mencionados en la nota anterior, el caso que nos ocupa, el de Ramos ("per quatuor quartas ducat...") es casi trivial. El canon contaria con una practica relativamente habitual en el Renacimiento, el cambio de armadura y la ausencia en la escritura de las alteraciones que un buen interprete debe recomponer. Interprete. ahora, en un doble sentido, musical y del propio enigma del canon. Ahora, por analogia, podemos establecer que si se cambia de armadura en la misma voz, la voz inicial del canon debe ser la más grave para que tenga un bemol más que la segunda en entrar, la cual tendrá uno más que la siguiente, etc. etc. Si, por el contrario, son las otras voces las que en las sucesivas entradas aparecen una cuarta mas agudas respectivamente (con un bemol más), será la voz aguda la que inicie el canto. Existen ambas posibilidades.

Hay más. Según Lowinsky, la pieza de Josquin podria ser la primera en recorrer el circulo completo de quintas, o sea, de usar todas las alteraciones cromáticas. El continuo cambio de tonalidad estarla simbólicamente asociado con la inestabilidad (la mutatio) de la donna movile Fortuna, idea que aparece perfectamente establecida en el Caliope legale del contemporáneo y enemigo de Ramos, el carmelita inglés $\mathrm{J}$. Hothby. Lo más significativo es que la obra de Josquin esta compuesta precisamente en los dos modos del canon de Ramos asociados con Venus y Júpiter: la primera parte del tenor en el Lidio, la segunda en el hipolidio, produciendo lo que se conoce como tonus mixtus. Donde se mostraria ya de forma clara la necesidad del circulo de quintas cerrado es, según Lowinsky, en el famoso Duo Quidnam Ebrietas de A. Willaert de $1518^{25}$. La composición termina en la séptima Mi-Re.

Colocando las correspondientes alteraciones no escritas, el Mi apareceria con doble bemol para que se de la octava Re-re y evitar de esta forma la comma pitagórica. Se habria recorrido el círculo de quintas completo. Muy audazmente. Lowinsky compara a Willaert

\footnotetext{
${ }^{25}$ E. Lowinsky. "Willaert's Chromatic 'Duo' Reexamined". Tyjdschrift voor Muziek wetenschap, 18 (1956). El articulo es una critica a los de J. S. Levitan. "Adrian Willaert's Famous Duo Quidan Ebrletas. A Composition wich closes apparently with the Interval of a Seventh". Tijdschrift van de Vereniging voor Nederlandsche Mualekgeschiedenis XV (1939) y "Echoes of Adrian Willaert's Chromatic 'Duo' in Sixteenth and SeventeenthCentury Compositions". en H. Powers ed.. Studies in Music History. Essays for Oliver Strunk. Princeton Un. Prest, 1968.
} 
con Sebastián Elcano; ambos dieron la vuelta por vez y en la misma fecha, el uno al mundo, el otro al circulo de quintas.

EL tercer experimento se debe a un alemán, Mathias Greiter. quien en 1553 compone una pieza a cuatro voces, Passibus ambiguis basada en una chanson anterior, Fortuna desperata ${ }^{26}$. El compositor hace recorrer a la frase del tenor todas las tonalidades mediante mutaciones hexacordales como ilustración del texto: "Passibus ambiguis Fortuna volubilis errat/ Et manet in nullo certa tenaxque loco". Lowinsky supone que en todas estas piezas es necesario el temperamento igual para poder recorrer el circulo completo de quintas. Pues bien, si las consideraciones que hemos hecho sobre el canon de Ramos apuntan en la dirección deseada. seria la primera obra conocida, carente además de un texto que lo indique, en recorrer el circulo de quintas, anterior a los experimentos que menciona Lowinsky ${ }^{27}$. Al usar todas las alteraciones, Ramos habria desafiado la afinación pitagórica de su época tanto como la concepción modal, justo aquellas dos innovaciones que le crearon justa fama y multitud de criticas. Pero habria que hacer otra critica a las formulaciones de Lowinsky. Para recorrer el circulo de quintas no es imprescindible el temperamento igual, sino cualquier tipo de temperamento circular, aunque no sea regular (con todas las quintas iguales). Hay varios en el Renacimiento ${ }^{28}$. Entre ellos, el "squismático" del propio Ramos que necesitaria temperarse ligeramente para evitar la quinta falsa entre Sol y Re. O quizás Ramos pensaba en un temperamento igual que no pudo establecer racionalmente (lo haría Salinas por primera vez) y lo expreso simbólicamente mediante su canon. Es una ironia que Ramos haya pasado durante mucho tiempo por ser el inventor del temperamento igual a partir nada mas que de su obra teórica ${ }^{29}$.

\footnotetext{
${ }^{26}$ E. Lowinsky. "Mathaeus Greiter's Fortuna: An Experiment in Chromaticism and in Musical lconography" I. Musical guarterly. 42 (1956) y II. Ibidem, 43 (1957).

27 Lo insinúa el editor del cancionero donde aparece el canon de Ramos. H. Mayer Brown, op. cit.

28 J. Goldáraz, op. cit.

29 Entre otros. el P. Martini. Fétis. J. Jeans, etc. F. J. León Tello analiza en detalle la cuestión en Estudios de Historia de la teroría musical. C.S.I.C.., 1991 (reimpresión).
} 
Si son ciertas nuestras suposiciones, el canon de Ramos se prodiga en una autentica polución de lo circular; dos círculos intramusicales, el de la octava y el de quintas. Otros dos "extramusicales", el cosmos y la rueda de la Fortuna. Unificando ambos pares, el propio canon en su doble expresión musical y pictórica.

Podria haber más interpretaciones. C. Terni, por ejemplo, nos ofrece una de índole numerológico ${ }^{30}$. El número de palabras de la clave son 20, que en el gamut guidoniano es Si o Sib. Las palabras que rodean la clave tienen el siguiente nümero de letras: Oriens $=$ 6. Mundus $=6$. Sumadas dan 12. Meridion $=8$, Et Musica $=8$. Sumadas dan 16. Occidens $=8$, Et totus conceptus $=16$. Sumadas dan 24. Septentrion $=11$, Bartholumeus Rami, 12 y 4 respectivamente. Sumadas dan 27. Entre estos números pueden establecerse ahora las relaciones numéricas de las consonancias $2 / 1$, la octava, $3 / 2$, quinta, $4 / 3$. cuarta, etc., hasta el tritono, necesario en el ámbito de una octava, vendria representado por el numero 27 . Seria fácil apuntar otros simbolismos: uno, evidente, aplicar el texto de la clave a la música y explorar su expresión "poético-musical". Otro, comparar la pieza con otras contemporáneas que tiendan al cromatismo, se relacionen iconográficamente con la Fortuna, etc. (hay ejemplos en abundancia, de Isaac, Agrícola. Obrecht, etc., alguno dentro incluso del propio cancionero florentino).

Para finalizar, señalar el programa iconográfico tan unificado que presenta la ilustración de Ramos ${ }^{31}$. La cita horaciana refleja el carácter de la música: como el cantor del texto, el canon es difícil de saber cómo comienza, por ser un canon enigmático, y dificil de finalizar una vez comenzando, porque es un canon circular. perpetuo; hay que tener en ambos casos la clave. El círculo musical representa el mundo, compuesto de notas musicales; mundo y música son lo mismo, como indica uno de los lemas. La imagen visual y musical coinciden en su simbolismo.

\footnotetext{
${ }^{30}$ C. Terni. op. cit.

31 Vid. H. Mayer Brown, op. cit.
} 